\title{
Computerized Axial Tomography Findings in Children with Afebrile Seizures: A Hospital Based Study at Eastern Nepal
}

\author{
Prakash Poudel, ${ }^{1}$ Mukesh Kumar Gupta, ${ }^{2}$ Shyam Prasad Kafle ${ }^{1}$ \\ ${ }^{1}$ Department of Pediatrics and Adolescent Medicine, ${ }^{2}$ Department of Radiodiagnosis and Imaging, B.P. \\ Koirala Institute of Health Sciences, Sunsari, Nepal
}

\begin{abstract}
Background: Computerized Tomography can be performed in resource limited areas where Magnetic Resonance Imaging is less practical. This study was conducted to find out the proportion of cases with abnormal CT scan and findings of CT scan in children with afebrile seizures in a resource limited area.

Methods: This prospective study was conducted from $1^{\text {st }}$ July 2009 to $31^{\text {st }}$ March 2014 in a university hospital of Nepal. Patients ( 1 month to 20 years of age) presenting with history of afebrile seizure were included. Neuroimaging was prescribed; children were treated and followed-up as per standard guideline. Data were analyzed using SPSS 16.0. Results: There were 447 children with afebrile seizures included in the study. Male to female ratio was 1.6:1. Median age at presentation was 84 (interquartile range 36-144) months. CT scan was done in 321 (71.8\%) cases. CT was abnormal in 143 cases, accounting for $32.0 \%$ out of total cases and $44.5 \%$ out of investigated cases. Among investigated cases, common CT findings were atrophy (13.4\%), neurocysticercosis $(12.1 \%)$, structural abnormalities $(4.4 \%)$, stroke $(3.7 \%)$, post-encephalitis changes $(3.1 \%)$, nonspecific calcification $(1.6 \%)$, tuberculoma $(1.2 \%)$, tumor $(0.9 \%)$, neurocutaneous syndromes $(0.9 \%)$, hydrocephalus $(0.9 \%)$ and other findings $(2.2 \%)$.

Conclusions: In a resource limited area CT scan is a valuable alternative tool in evaluating a child with afebrile seizure. Majority of these children have remote symptomatic seizures and the underlying brain pathologies can be well detected by CT scan.

Keywords: Child; seizure; X-ray computed tomography.
\end{abstract}

\section{INTRODUCTION}

Almost 1.5 to $5.0 \%$ of any population will have afebrile seizures at some time. ${ }^{1}$ Structural neuroimaging plays an important role in the evaluation, management, and treatment of the child with epilepsy.

Magnetic Resonance Imaging (MRI) is considered the imaging modality of choice. ${ }^{2}$ World Health Organization estimates that, of the 50 million people with epilepsy in the world, $80.0 \%$ live in developing countries where MRI is not easily available or affordable. ${ }^{3}$ In those areas, Computerized Tomogrpahy (CT) scan is more widely available than MRI, is less expensive, and is less likely to require sedation for younger children.

There is paucity of information on use of neuroimaging in children with epilepsy in developing countries.
Purpose of this study was to explore $\mathrm{CT}$ scan findings in children suffering from afebrile seizures, to find out the proportion of cases with abnormal CT scan and to find out the positivity rate of $\mathrm{CT}$ scan in children with afebrile seizures who were subjected to CT scan in a resource limited area.

\section{METHODS}

This was a prospective study carried out from $1^{\text {st }}$ July 2009 to $31^{\text {st }}$ March 2014. The study was conducted in pediatric and adolescent neurology clinic at B.P. Koirala Institute of Health Sciences, Dharan, Nepal. Taking in account of around $30 \%$ children with expected seizure to have abnormal CT scan ${ }^{4,5}$ and estimated sensitivity of $30 \%$ with precision of $\pm 10.0 \%$, a minimum of 280 seizure cases with $\mathrm{CT}$ scan were required for the study. 
Inclusion criteria were children from one month to 20 years of age, presenting to pediatric neurology clinic and presence of at least one afebrile unprovoked seizure. Neonates, children with febrile convulsion, acute symptomatic seizures like seizures due to acute febrile encephalopathy, acute metabolic disturbance, electrolyte disturbance, drug overdose and poisoning etc. and children with psychogenic non epileptic seizures were excluded from the study.

Cases meeting the inclusion criteria were sampled for the study by consecutive sampling technique. Detail information with regard to demographic profile, history, seizure type, clinical examination findings, developmental status, СT scan findings and other important parameters were recorded in predesigned data collection sheet. Family history of seizure was asked. Presence of seizure in first or second degree relative was considered as positive family history of seizure.

SIGN (Scottish Intercollegiate Guidelines Network) guideline was followed for ordering investigations like inter-ictal electroencephalography (EEG) and neuroimaging. ${ }^{6}$ Inter-ictal EEG was advised in subjects with first afebrile seizure or recurrent afebrile seizures. Although 0.3 Tesla MRI is available in our study site, most of the subjects cannot afford it and it requires deep sedation for long time that makes it less practical for children who visit neurology clinic on outpatient basis. Therefore, we ordered CT scan when neuroimaging was required. CT scan was not ordered for single episode of brief generalized seizure, primary generalized epilepsies and for benign rolandic epilepsy. For other seizures, CT scan was ordered. CT scan reported by radiologist having minimum qualification of MD. Whenever patient was referred from outside with CT reported elsewhere, the reliability of report was cross checked by radiologist working in the study hospital. Proportion of abnormal CT scan among total seizure cases was calculated as percentage. Positivity rate of CT scan among seizure cases was also calculated as proportion of cases with abnormal scan out of total cases who were subjected to CT scan. MRI was not advised and not done in cases with normal CT scan because of issues like requirement of prolonged sedation and cost. EEG was reported by principal investigator who is trained in clinical neurophysiology and regularly reports EEG of children at the institution. EEG was deemed as abnormal when there were generalized or focal abnormalities like interictal epileptiform discharges or slow wave abnormality.

Diagnosis and classification of seizure was made on electroclinical ground whenever possible. When interictal EEG showed focal or multifocal discharges, seizure was considered as focal irrespective of clinical seizure semiology. When interictal EEG was normal, characterization of seizure as focal or generalized was done solely based on clinical description of seizure. Epileptic encephalopathies like West Syndrome and Lennox Gastaut Syndrome were considered as generalized seizures. Seizure was classified using International Classification of Epileptic Seizures proposed by ILAE in 1981. ${ }^{7}$

Ethical clearance was obtained from Institutional Ethical Review Board of the university hospital where study was conducted. Data were entered and screened for error in MS Excel. The analysis was done using SPSS 16.0 statistical software.

\section{RESULTS}

Study included patients presenting to pediatric and adolescent neurology clinic for seizure. There were 447 children with afebrile seizures. Male to female ratio was 3:2 (276 male and 171 female). Median age at presentation was 84 (interquartile range 36 to 144) months. Median age at onset of seizure was 46 (interquartile range 12 to 102) months. Table 1 shows baseline characteristics of children.

\begin{tabular}{|c|c|c|}
\hline Characteristics & $\begin{array}{l}\text { Number } \\
\text { (total } \\
\text { cases 447) }\end{array}$ & Percentage \\
\hline $\begin{array}{l}\text { Seizure onset below } 5 \\
\text { years of age }\end{array}$ & 282 & 63.1 \\
\hline $\begin{array}{l}\text { History of status } \\
\text { epilepticus }\end{array}$ & 98 & 21.9 \\
\hline $\begin{array}{l}\text { Presentation with first } \\
\text { seizure }\end{array}$ & 80 & 17.9 \\
\hline $\begin{array}{l}\text { Presence of developmental } \\
\text { delay }\end{array}$ & 137 & 30.6 \\
\hline History of birth asphyxia & 71 & 15.9 \\
\hline Family history of seizure & 51 & 11.4 \\
\hline $\begin{array}{l}\text { Abnormal neurological } \\
\text { examination }\end{array}$ & 152 & 34.0 \\
\hline \multicolumn{3}{|l|}{ Head circumference } \\
\hline Microcephaly & 58 & 13.0 \\
\hline Macrocephaly & 4 & 0.9 \\
\hline Presence of motor deficit & 105 & 23.5 \\
\hline
\end{tabular}




\begin{tabular}{|lcc|}
\hline Tone abnormality & & \\
Hypertonia & 82 & 18.3 \\
Hypotonia & 15 & 3.4 \\
\hline $\begin{array}{l}\text { Electroencephalogram } \\
\text { Normal }\end{array}$ & 108 & 24.2 \\
Abnormal & 277 & 62.0 \\
Not done* & 62 & 13.9 \\
Cerebral palsy & 86 & 19.2 \\
Type of seizure & & \\
Generalized & 217 & 48.5 \\
Focal & 230 & 51.5 \\
\hline *Because of no indication or non-compliance & \\
\hline
\end{tabular}

CT scan was done in $321(71.8 \%)$ cases. In rest of the cases, neuroimaging was not done because either it was not indicated or because of other problems, such as loss to follow up, inability to afford, non-compliance etc. CT scan was abnormal in 143 cases accounting for $32.0 \%$ out of total cases. CT scan positivity rate was $44.5 \%$ among the investigated cases. Major CT scan findings are presented in Table 2 and further details of the common findings are presented in Table 3.

\begin{tabular}{|c|c|c|c|}
\hline CT scan finding & Number & $\begin{array}{l}\% \text { out } \\
\text { of total } \\
\text { cases } \\
(447)\end{array}$ & $\begin{array}{l}\% \text { out of } \\
\text { investigat- } \\
\text { ed cases } \\
(321)\end{array}$ \\
\hline Atrophy & 43 & 9.6 & 13.4 \\
\hline Neurocysticercosis & 39 & 8.7 & 12.1 \\
\hline $\begin{array}{l}\text { Structural abnor- } \\
\text { mality }\end{array}$ & 14 & 3.1 & 4.4 \\
\hline Stroke & 12 & 2.7 & 3.7 \\
\hline $\begin{array}{l}\text { Post encephalitis } \\
\text { changes }\end{array}$ & 10 & 2.2 & 3.1 \\
\hline $\begin{array}{l}\text { Nonspecific calci- } \\
\text { fication }\end{array}$ & 5 & 1.1 & 1.6 \\
\hline Tuberculoma & 4 & 0.9 & 1.2 \\
\hline Tumor & 3 & 0.7 & 0.9 \\
\hline $\begin{array}{l}\text { Neurocutaneous } \\
\text { syndromes }\end{array}$ & 3 & 0.7 & 0.9 \\
\hline Other findings & 10 & 2.2 & 3.1 \\
\hline $\begin{array}{l}\text { CT scan not done/ } \\
\text { not available }\end{array}$ & 126 & 28.2 & -- \\
\hline Total & 447 & 100.0 & 100.0 \\
\hline
\end{tabular}

\section{Table 3. Details of major CT scan findings.}

Major find- Details Number
ings
ings

within major findings

\begin{tabular}{|c|c|c|c|}
\hline \multirow{5}{*}{$\begin{array}{l}\text { Atrophy } \\
(n=43)\end{array}$} & Diffuse atrophy & 29 & 67.4 \\
\hline & Hemiatrophy & 10 & 23.3 \\
\hline & Focal atrophy & 4 & 9.3 \\
\hline & $\begin{array}{l}\text { Without encepha- } \\
\text { lomalacia }\end{array}$ & 34 & 79.1 \\
\hline & $\begin{array}{l}\text { With cystic en- } \\
\text { cephalomalacia }\end{array}$ & 9 & 20.9 \\
\hline \multirow{3}{*}{$\begin{array}{l}\text { Neurocyst- } \\
\text { icercosis } \\
(n=39)\end{array}$} & $\begin{array}{l}\text { Ring enhancing } \\
\text { lesion }\end{array}$ & 25 & 64.1 \\
\hline & $\begin{array}{l}\text { Calcified granu- } \\
\text { loma }\end{array}$ & 13 & 33.3 \\
\hline & Vesicular stage & 1 & 2.6 \\
\hline \multirow[t]{3}{*}{ Tumor $(n=3)$} & $\begin{array}{l}\text { Primitive neuroe- } \\
\text { ctodermal tumor }\end{array}$ & 1 & 33.3 \\
\hline & $\begin{array}{l}\text { Hypothalamic } \\
\text { hamartoma }\end{array}$ & 1 & 33.3 \\
\hline & Ganglioglioma & 1 & 33.3 \\
\hline \multirow{2}{*}{$\begin{array}{l}\text { Neurocutane- } \\
\text { ous syn- } \\
\text { dromes }(n=3)\end{array}$} & Tuberous sclerosis & 2 & 66.7 \\
\hline & $\begin{array}{l}\text { Sturge weber } \\
\text { syndrome }\end{array}$ & 1 & 33.3 \\
\hline \multirow{8}{*}{$\begin{array}{l}\text { Structural } \\
\text { abnormality } \\
(n=14)\end{array}$} & $\begin{array}{l}\text { Agenesis of cor- } \\
\text { pus callosum }\end{array}$ & 4 & 28.6 \\
\hline & $\begin{array}{l}\text { Lissencephaly } \\
\text { and pachygyria }\end{array}$ & 2 & 14.3 \\
\hline & Arachnoid cyst & 2 & 14.3 \\
\hline & $\begin{array}{l}\text { Vascular malfor- } \\
\text { mation }\end{array}$ & 2 & 14.3 \\
\hline & Schizencephaly & 1 & 7.1 \\
\hline & $\begin{array}{l}\text { Grey matter } \\
\text { heterotopias }\end{array}$ & 1 & 7.1 \\
\hline & Porencephaly & 1 & 7.1 \\
\hline & $\begin{array}{l}\text { Agenesis of sep- } \\
\text { tum pellucidum }\end{array}$ & 1 & 7.1 \\
\hline \multirow[t]{2}{*}{ Stroke $(n=12)$} & Infarction & 10 & 83.3 \\
\hline & $\begin{array}{l}\text { Sinus venous } \\
\text { thrombosis }\end{array}$ & 2 & 16.7 \\
\hline $\begin{array}{l}\text { Post encepha- } \\
\text { litis changes } \\
(n=10)\end{array}$ & $\begin{array}{l}\text { Areas of hy- } \\
\text { podenisties with } \\
\text { gliosis }\end{array}$ & 10 & 100.0 \\
\hline
\end{tabular}


Computerized Axial Tomography Findings in Children with Afebrile Seizures

\begin{tabular}{|c|c|c|c|}
\hline \multirow[t]{5}{*}{ Other $(n=10)$} & $\begin{array}{l}\text { White matter } \\
\text { hypodenisties of } \\
\text { unknown etiology }\end{array}$ & 3 & 30.0 \\
\hline & Hydrocephalus & 3 & 30.0 \\
\hline & $\begin{array}{l}\text { Degenerative } \\
\text { brain disease }\end{array}$ & 2 & 20.0 \\
\hline & $\begin{array}{l}\text { Multifocal hemor- } \\
\text { rhagic contusion }\end{array}$ & 1 & 10.0 \\
\hline & Gliosis & 1 & 10.0 \\
\hline
\end{tabular}

\section{DISCUSSION}

Epilepsy is a common disorder, and over one half of epileptic patients develop seizures before the age of 16 years. Head CT is often requested in this age group to establish etiology, to provide prognosis, and to plan appropriate mangement. In patients with epilepsy, abnormalities localized on CT are of particular clinical relevance because some cases may be amenable to surgical intervention. The proportion of patients with seizures found on CT to require surgical intervention varies from $1-2 \%$ in children. ${ }^{4,5}$

In our study, CT scan was done in 321 (71.8\%) cases. In rest of the cases, neuroimaging was not done because either it was not indicated or because of other problems like loss to follow up, inability to afford and non-compliance. CT scan was abnormal in 143 cases, accounting for $32.0 \%$ out of total cases and $44.5 \%$ out of investigated cases. It shows that positivity rate of CT scan is reasonably good in resource limited areas where MRI is not easily available or less practical. In study done including all age groups, proportion of cases with CT abnormalities range from $26 \%$ to $54 \%{ }^{4,8-10}$ In studies done in children, the positivity rate of $\mathrm{CT}$ scan were variable, ranging from $21.0 \%$ to $41.7 \%$ in developed countries and as high as $70.0 \%$ in Indian subcontinent. The positivity rate of CT scan was $21.0 \%$ out of investigated cases in study by Gibbs et al., ${ }^{8} 41.7 \%$ in study by Ladurner et al., ${ }^{11} 30.0$ $\%$ in study by Bachman et al., ${ }^{4}$ and $39.5 \%$ in study by Al-Sulaiman et al. ${ }^{12}$ This wide variation in positivity rate of CT scan might be because of bias in selection of cases for ordering CT scan. Another reason could be high prevalence of neurocysticercosis (NCC) and perinatal brain injury in developing world, especially Indian subcontinent.

Atrophy was the most common abnormality detected in our children comprising of $9.6 \%$ out of total cases and $13.4 \%$ out of investigated cases. Most of these cases with atrophy were suffering from cerebral palsy due to early brain insult, mainly birth asphyxia. Cerebral palsy was present in $19.2 \%$ children in our study. Therefore, the cause of atrophy was mainly due to birth asphyxia

leading to hypoxic brain damage. Birth trauma has been one of the most common causes of seizures in many other studies. ${ }^{13,14}$ Similar to our finding, in study by Gibbs et al., atrophy was the most common CT scan abnormality that was found in $9.0 \%$ of children suffering from seizure. ${ }^{8}$ CT revealed generalized atrophy in $6.0 \%$ and focal atrophy in $7.0 \%$ children in study by Bachman et al. ${ }^{4}$

NCC was the second most common abnormality detected by CT scan in our study. NCC is a major cause of neurological illness worldwide. In Nepal and surrounding areas as well as other parts of developing world, NCC is a major public health hazard causing substantial neurological morbidity and economic burden. It is the most common identifiable cause of partial seizure especially in the children of developing world and it is recommended to consider NCC as a differential diagnosis of new onset partial seizure in a child living in an area where NCC is endemic. ${ }^{15-17}$

Structural abnormalities including neuronal migration defects, post encephalitis changes and stroke were other common abnormalities detected in CT scan in our study comprising of $3.1 \%, 2.7 \%$ and $2.2 \%$ out of total cases and $4.4 \%, 3.7 \%$ and $3.1 \%$ out of investigated cases, respectively. Tumor, tuberculoma, non-specific calcifications and neurocutaneous syndromes were other less common findings in the study. Bachman et al. studied CT scan of 98 children with seizure and found atrophy as the most common finding. Other common findings in the study were hydrocephalus, porencephaly, tumor, calcifications, and post-operative changes. ${ }^{4}$

Tumors were detected in three children in our study. They were ganglioglioma, primitive neuroectodermal tumor (PNET) and hypothalamic hamartoma in one child each. Berg et al evaluated 613 children with seizure in the United States of America and used neuroimaging (CT or MRI or both) in 388 children. They also found tumors in two children, one each ganglioglioma and dysembryoplastic neuroepithelial tumor (DNET). They detected neurocutaneous syndrome in eight children. But NCC was not present in any child. ${ }^{18}$ When comparing our findings with $\mathrm{CT}$ findings in patients from other parts of world, proportions of findings of non-infective origin, such as birth injury, stroke, malformations, neurocutaneous syndromes and incidental findings are common findings everywhere. Proportion of brain atrophy due to perinatal brain injury seems higher in developing countries. However, findings of infective origin, such as post encephalitis changes, NCC and tuberculoma, were conspicuously more common in our study, in studies done in other parts of Asia, and other 
developing countries. ${ }^{14,19,20}$ However, these neuroimaging findings were rare to absent in the studies done in developed countries. ${ }^{13,18}$

This study has some limitations. Guideline for neuroimaging could not be strictly followed because many children with indication for neuroimaging did not have neuroimaging done due to noncompliance and loss to follow up before investigation. CT scan was done in some children without indication for neuroimaging to decrease the parental anxiety. Children who were referred to our center already had CT scan done from outside irrespective of the indication. In order to determine the yield of CT scan and to justify its use in resource limited settings despite its radiation hazard, it would be necessary to know the percent of cases missed by doing CT scan only. In this study, MRI was not done in cases with normal CT scan because of issues, such as requirement of prolonged sedation, unavailability and cost. A prospective, population-based, longitudinal, study covering different large geographic areas and with strict adherence to established guidelines and additional use of MRI are needed to further elucidate the value and yield of CT scan while evaluating a child with afebrile seizure in resource constrained settings.

The present study focuses on common neuroimaging findings and value of CT scan in evaluation of children with afebrile seizure living in a resource limited area. Significant proportion of children with seizures in these areas have seizures because of consequences of perinatal brain injury, central nervous system infection, NCC, stroke and various other structural abnormalities. Underlying pathology in brain due to these conditions can be well detected by CT scan. Some differences exist in the proportions of common underlying causes of seizure as detected by CT scan between a developing and developed countries. Brain pathologies as consequences of perinatal brain injury and infective diseases are detected by CT scan in higher proportions ,resource limited areas indicating higher prevalence of these problems there. In the era of MRI, CT scan is rarely used in developed areas of world because of superiority of MRI. However, MRI might not be easily available, affordable and practical in resource poor setting. In these areas, CT scan is still a valuable tool in evaluating a child with afebrile seizure and positivity rate of $\mathrm{CT}$ scan is reasonably good.

\section{CONCLUSIONS}

CT scan is a valuable alternative tool in evaluating a child with afebrile seizure. Significant proportion of children with afebrile seizure in such area have remote symptomatic seizures because of consequences of perinatal brain injury, CNS infection, NCC, stroke and various other structural abnormalities.

\section{ACKNOWLEDGEMENTS}

We thank and acknowledge all the parents and children who participated in this study and the resident doctors who managed patients in neurology clinic and helped in data collection.

\section{REFERENCES}

1. Sander JWAS, Shorvon SD. Epidemiology of the epilepsies. J Neurol Neurosurg Psychiatry. 1997Jan;62(6):679. [PubMed]

2. Gaillard WD, Chiron C, Cross JH, Harvey AS, Kuzniecky R, Hertz-Pannier L, et al. Guidelines for imaging infants and children with recent-onset epilepsy. Epilepsia. 2009;50(9):2147-53. [PubMed]

3. WHO. Mental health: new understanding, new hope [Internet]. World Health Organization; 2001 [cited 2016 Jun 2]. Available from: http://www.who.int/whr/2001/ en/whr01_en.pdf

4. Bachman DS, Hodges FJ, Freeman JM. Computerized axial tomography in chronic seizure disorders of childhood. Pediatrics. 1976;58:828-32. [PubMed]

5. Yang PJ, Berger PE, Cohen ME, Duffner PK. Computed tomography and childhood seizure disorders. Neurology. 1979;29(8):1084-8. [PubMed]

6. Scottish Intercollegiate Guidelines Network. Diagnosis and management of epilepsies in children and young people: a national clinical guideline [Internet]. Scottish Intercollegiate Guidelines Network; 2005 [cited 2 June 2016]. Available from: http://www.epilepsyscotland.org. uk/pdf/sign81.pdf

7. Proposal for Revised Clinical and Electroencephalographic Classification of Epileptic Seizures. Epilepsia. 1981;22(4):489-501. [PubMed]

8. Gibbs J, Appleton R, Carty H, Beirne M, Acomb B. Focal electroencephalographic abnormalities and computerised tomography findings in children with seizures. J Neurol Neurosurg Psychiatry. 1993;56(4):369-71. [PubMed]

9. Bauer G, Mayr U, PalluaA. Computerized axial tomography in chronic partial epilepsies. Epilepsia. 1980;21(3):22733. [PubMed] 
10. Ramirez-Lassepas M, Morillo L, Gumnit R, Cipolle R. Value of computed tomographic scan in the evaluation of adult patients after their first seizure. Ann Neurol. 1984;15(6):536-43. [PubMed]

11. Ladurner G, Fritsch G, Sager W, Iliff LD, Lechner H. Computer tomography in children with epilepsy. Eur Neurol. 1980;19(3):180-4. [PubMed]

12. Al-Sulaiman AA, Ismail HM. Clinical pattern of newlydiagnosed seizures in Saudi Arabia: a prospective study of 263 children. Childs Nerv Syst. 1999;15(9):468-71. [Pubmed]

13. Granieri E, Rosati G, Tola R, Pavoni M, Paolino E, Pinna L, et al. A Descriptive Study of Epilepsy in the District of Copparo, Italy, 1964-1978. Epilepsia. 1983;24(4):502-14. [PubMed]

14. Placencia M, Shorvon S, Paredes V, Bimos C, Sander J, Suarez J, et al. Epileptic seizures in an Andean region of Ecuador. Incidence and prevalence and regional variation. Brain. 1992;115(Pt 3):771-82. [PubMed]

15. Shrestha BM. Childhood Neurocysticercosis: ClinicoRadiological Profile and Outcome. J Nepal Paediatr Soc. 2008;28(1):14-6.
16. Basu S, Ramchandran U, Thapliyal A. Clinical profile and outcome of pediatric neurocysticercosis: a study from Western Nepal. J Pediatr Neurol. 2007;5(1):45-52. [Pubmed]

17. RajshekharV, Joshi DD, Doanh NQ, van De N, Xiaonong Z. Taenia solium taeniosis/cysticercosis in Asia: epidemiology, impact and issues. Acta Trop. 2003;87(1):53-60. [PubMed]

18. Berg AT, Testa FM, Levy SR, Shinnar S. Neuroimaging in children with newly diagnosed epilepsy: a communitybased study. Pediatrics. 2000;106(3):527-32. [PubMed]

19. Coe CJ. Brain computerized tomographic findings in various epileptic children. Yonsei Med J. 1988;29(4):3215. [PubMed]

20. Patel PJ, Kolawole TM, Mahdi AH, Qteishat WA. Computed tomography (CT) scan findings in children with seizures only. Acta Neurol Scand. 1986;74(2):165-6. [PubMed] 